\title{
Long term patient satisfaction and quality of life with AMS700CX inflatable penile prosthesis
}

\author{
Antonio Vitarelli ${ }^{1}$, Lucia Divenuto ${ }^{1}$, Francesca Fortunato ${ }^{2}$, Antonio Falco ${ }^{3}$, \\ Vincenzo Pagliarulo ${ }^{1}$, Gabriele Antonini ${ }^{4}$, Vincenzo Gentile ${ }^{4}$, Alessandro Sciarra ${ }^{4}$, \\ Stefano Salciccia ${ }^{4}$, Salvatore Sansalone ${ }^{5}$, Maria Rosaria Di Placido ${ }^{4}$, \\ Giulio Garaffa ${ }^{6}$, Arcangelo Pagliarulo ${ }^{1}$ \\ 1 "Urologia II Universitaria", Department of Emergency and Transplant, Section of Urology and Andrology, \\ University Hospital "Azienda Ospedaliera Policlinico", Bari, Italy; \\ ${ }^{2}$ Department of Medical Sciences and Occupational Medicine, Section of Hygiene, University of Foggia, Italy; \\ ${ }^{3}$ Epidemiologic Observatory of Puglia, Italy; \\ ${ }^{4}$ Department of Urology, University "La Sapeinza", Rome, Italy; \\ ${ }^{5}$ Department of Urology, "Tor Vergata" University, Rome, Italy; \\ ${ }^{6}$ St. Peter's Andrology and the Urology Centre, Broomfield Hospital, Chelmsford, UK.
}

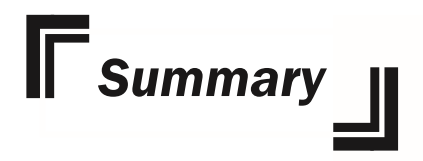

Objective: Penile prosthesis implantation is the solution of choice in patients who have failed or present contraindication to the use of all conservative treatment for erectile dysfunction (ED). Overall, satisfaction rates are high, with more than $80 \%$ of patients and partners fully satisfied with cosmetic and functional result of surgery. Chronic postoperative pain, penile shortening, soft or hyposensitive glans, pencil like penis syndrome and difficulty to cycle the device represent the most common causes of patient's dissatisfaction. Satisfaction rates are better assessed with the use of validated questionnaires such as the International Index of Erectile Function (IIEF) and the Erectile Dysfunction Inventory of Treatment Satisfaction (EDITS) The aim of our study was to analyze the long-term mechanical reliability of the AMS 700CX/CXM inflatable penile prosthesis and the patient's satisfaction rate using IIEF and EDITS questionaire as standard reference.

Materials and methods: A retrospective case notes review of all patients who have undergone implantation of a three pieces inflatable penile prosthesis AMS 700 CX and CXR between October 1997 and December 2010. Overall, 80 patients have undergone implantation of 3 pieces inflatable penile prosthesis AMS 700 CX InhibiZone. Patients have been administered the IIEF-5 and EDITS questionnaires in combination with a non validated 9 domain questionnaire that assesses penile rigidity, sensation, orgasmic function, frequency of intercourse, impact of surgery on the quality of life, satisfaction rate.

Results: Overall 10 years survival estimate according to the Kaplan Meier method of AMS 700 CX touch pump and AMS 700 CX momentary squeeze pump are respectively $77.6 \%$ and $82.5 \%$. The median postoperative IIEF5 and EDITS score were respectively 21.46 and 73.11, which show a high level of satisfaction. 59 patients (90.8\%) were able to cycle the device and were engaging in penetrative sexual intercourse.

Conclusions: Penile prosthesis implantation yields excellent results in terms of cosmetic and functional outcome and therefore has a significant impact on patients' satisfaction, sex life and overall quality of life. Overall, long term reliability has been significantly improved and complication rates are low in the hands of experienced surgeons.

KEY WORDS: Penile prosthesis; Erctile disfunction; Impotence; Questionnaires.

\section{INTRODUCTION}

Penile prosthesis implantation is the solution of choice in patients who have failed or present contraindication to the use of all conservative treatment for erectile dysfunction
(ED). Overall, 25-30\% of patients with ED will fail to respond to phosphodiesterase type 5 inhibitors (PDE5i) and will therefore be offered intracavernosal injection (ICI) 
of prostaglandin E (PGE). Since ICI is associated with a high rate of drop out, around 10-15\% of patients with ED will be candidate for penile prosthesis implantation (1). Although prosthetic surgery in virgin corpora is associated with higher satisfaction rates in patients and partners than PDE5i, intra and postoperative complications are not uncommon and therefore the procedure should be carried out only by a large volume surgeon.

Inflatable device have been initially introduced by Scott in 1973 (2) and now are available in a two and three pieces version. In general, inflatable penile prosthesis are associated with higher satisfaction rates among patients and partners than their semirigid counterpart as they allow girth expansion, thus preventing the risk of "pencil penis" syndrome, and can be deflated mimicking the flaccid penile state. The most widely used three pieces inflatable penile prostheses are produced by American Medical Systems (AMS, Minnetonka, Minnesota USA) and Coloplast (Coloplast Corporation, Humlebaek, Denmark). Since their initial introduction in 1973, three pieces inflatable penile prosthesis have undergone significant improvement in order to increase their long-term mechanical reliability and reduce the risk of infections. A major breakthrough has been the introduction by AMS of the AMS 700 CX model, which was characterized by controlled expansion cylinders. This has led to a reduction of mechanical failure from $62 \%$ to $15 \%$ at 5 years due to the reduced risk of aneurysmal dilatation of the cylinders (3). At present AMS is on the market with two varieties of three pieces inflatable penile prosthesis: the AMS $700 \mathrm{CX}$, and the AMS 700CXR, which presents narrow base cylinders and is designed for implantation in severely fibrotic corpora, where dilatation is difficult. The Coloplast counterparts are respectively the Titan and the Titan narrow base.

Another breakthrough has been the introduction by AMS of controlled girth and length expansion cylinders, This prosthesis, initially introduced on the market under the name of Ultrex, was associated with a high rate of erosion and mechanical failure and therefore has been improved and it is now available under the name of LGX (length and girth expansion) which allows a length expansion up to $4 \mathrm{~cm}$ and is associated with a 5 year survival of $94 \%$ in carefully selected patients (4). Also the pump has been redesigned, to render cycling easier and to reduce the incidence of mechanical failure. In particular, the introduction of the lock out valve has reduced the incidence of spontaneous autoinflation of the device and the momentary squeeze pump (MS) has allowed an easier deflation of the device (5-8).

Another breakthrough in the AMS implants has been the use of the Parilene coating of the cylinders, which renders the implant more resistant to friction and therefore reduces the risk of wearing, and the impregnation of the rods with InhibiZone, a combination of rifampicin and minocyclin, which has significantly reduced the risk of infection from $1,61 \%$ a $0,68 \%$ and from $2,41 \%$ a $1,36 \%$ respectively in virgin and revision implants (7-10). Indication for penile prosthesis implantation is refractory erectile dysfunction, which fails to respond to medical treatment. Also patients who have medical contraindications to the use of PDE5i, ICI and vacuum device are candidates for penile prosthesis implantation. The choice between an inflatable penile prosthesis depends on the patient's choice, funding, previous abdominal and genital surgery, body habitus and hand dexterity (1).

In general, poor hand dexterity and multiple abdominal surgeries are relative contraindications to the implantation of an inflatable penile prosthesis. Larger penises and physically active patients are instead better served with a three pieces inflatable device.

Adequate preoperative counseling is paramount, as excessively high patients expectations will lead to lower postoperative satisfaction rates. In particular, patients must be warned that stretched penile length is a good indicator of the postoperative penile length and that the procedure is irreversible.

Although the reliability of the device has been significantly improved, mechanical failure rates at 5 years still vary between 10 and $20 \%$. If the failure occurs in the early months, it not necessary to remove the entire device and the identification and exchange of the faulty component usually suffices. If the mechanical failure occurs after 2 years instead, it is advisable to exchange the entire device. Mechanical failure can occur in all components of the prosthesis, from the tubings, to the connectors, the pump, the reservoir and the cylinders.

Penile prosthesis infection still represents the most fearful complication, occurs in 1\% to 3\% of patients and is more common in case of diabetes, compromised immunitary system, neurological condition, revision surgery and fibrosis. In case of infection the entire device has to be removed and patients can be offered immediate (Mulcahy procedure) or delayed reimplantation. Erosion, necrosis, purulent discharge and systemic infection are contraindications for immediate reimplantation.

Erosion of the device is uncommon and occurs in 3\% to $6 \%$ of cases and it usually occurs at the navicular fussa or at the corona.

Overall, satisfaction rates are high, with more than $80 \%$ of patients and partners fully satisfied with cosmetic and functional result of surgery. Chronic postoperative pain, penile shortening, soft or hyposensitive glans, pencil like penis syndrome and difficulty to cycle the device represent the most common causes of patient's dissatisfaction (11). Satisfaction rates are better assessed with the use of validated questionnaires such as the International Index of Erectile Function (IIEF) and the Erectile Dysfunction Inventory of Treatment Satisfaction (EDITS) (12-13). The aim of our study was to analyze the long-term mechanical reliability of the AMS 700CX/CXM inflatable penile prosthesis and the patient's satisfaction rate using IIEF and EDITS questionaire as standard reference.

\section{MATERIALS AND METHOdS}

A retrospective case notes review of all patients who have undergone implantation of a three pieces inflatable penile prosthesis AMS $700 \mathrm{CX}$ and CXR between October 1997 and December 2010. This study was conducted after approval of the protocol from our department institutional committee and informed consent was obtained from all patients.

Overall, 80 patients have undergone implantation of 3 pieces inflatable penile prosthesis AMS 700 CX 
Table 1.

The domains of the non validated questionnaire.

\begin{tabular}{|c|c|c|c|c|}
\hline 1. Are you using the device? & 1 & 2 & 3 & 4 \\
\hline 2. Is the device easy to cycle? & 1 & 2 & 3 & 4 \\
\hline $\begin{array}{l}\text { 3. Did you notice an improvement } \\
\text { in your sexual life? }\end{array}$ & 1 & 2 & 3 & 4 \\
\hline 4. Are you satisfied? & 1 & 2 & 3 & 4 \\
\hline $\begin{array}{l}\text { 5. Would you advise a friend to undergo } \\
\text { the same procedure? }\end{array}$ & 1 & 2 & 3 & 4 \\
\hline 6. Would you undergo the same procedure? & 1 & 2 & 3 & 4 \\
\hline 7. Do you have sensation during intercourse? & 1 & 2 & 3 & 4 \\
\hline 8. Do you obtain adequate rigidity? & 1 & 2 & 3 & 4 \\
\hline 9. Do you achieve an orgasm? & 1 & 2 & 3 & 4 \\
\hline
\end{tabular}

InhibiZone; a tactile pump has been used in 42 patients and Momentary Sqeeze ${ }^{\circledR}$ pump in the remainder. The median age at the time of implantation was 56 years (range 40-77). The aetiology of ED was radical pelvic surgery in 32 patients (43.2\%), vasculogenic in $25(33.8 \%)$, Peyronie's Disease in 12 (16.2\%), spinal cord injury in 4 $(5.4 \%)$ and fibrosis post low flow priapism in 1 (1.4\%). Diabetes mellitus was present in 24 patients (20\%) and 6 had already undergone explantation of an infected penile prosthesis and presented with severe corporeal fibrosis. Implantation of the device has been carried out through a penoscrotal approach in 50 patients $(62.5 \%)$ and through an infrapubic one in the remainder. Implantation has been difficult in 7 patients due to severe corporeal fibrosis and a second subcoronal incision has been necessary in 4 cases to allow adequate distal dilatation. Patients have been administered the IIEF-5 and EDITS questionnaires in combination with a non validated 9 domain questionnaire that assesses penile rigidity, sensation, orgasmic function, frequency of intercourse, impact of surgery on the quality of life, satisfaction rate. Patients were invited to give a score between 1 and 4 for each of the questions (1: excellent; 2: good; 3: moderate; 4: poor) as reported in Table 1. Postoperative penile length has also been recorded.

\section{Statistical Analysis}

Statistical data analysis was done with the statistical software MedCalc Software Demo for Windows, version 9.3. The Kaplan-Meier method was used to analyze the survival of the AMS 700CX/CXM inflatable penile prostheses Also a Student's t-test was performed and a $\mathrm{P}$ value of $<0.05$ was considered to indicate a significant difference.

\section{RESULTS}

After a median follow up of 68.7 months (range 6- 164), infection of the device has occurred in 2 patients (2.5\%) and has required the removal of the device followed by delayed reimplantation at 6 months. Mechanical failure of the device has occurred in 10 patients (12.5\%) and was due to pump failure, cylinder rupture and fluid leak from the reservoir in respectively 5, 3 and 2 patients. All patients have been managed with complete exchange of the device. Erosion through the corona/glans occurred in
3 patients, through the scrotal skin in 1 and through the urethra in 1 , as shown in figure 1 and 2 . All the components of the implants have been removed in all patients. Overall, 65 patients have completed all the questionnaires. Both IIEF-5 and EDITS questionnaire have shown a mean improvement of the sexual function and of quality of life. The median postoperative IIEF5 and EDITS score were respectively 21,46 and 73,11 , which show a high level of satisfaction. 59 patients $(90,8 \%)$ were able to cycle the device and were engaging in penetrative sexual intercourse. With regards to the impact of surgery on the quality of life, 58 patients $(89,2 \%)$ were fully satisfied with the outcome of surgery, and 57 (57\%) were globally satisfied. 55 patients $(84,6 \%)$ would undergo surgery again and 57 would advise a friend to undergo the same treatment. Although patients who reported good sensitivity during intercourse scored higher at the EDITS $(74,6 \pm 19,2$; CI95\%: 69,4-79,7) and the IIEF-5 (21,7 $\pm 5,2$; CI95\%: 20,2-23,2) questionnaires than patients who had poor sensation [EDITS (63,8 \pm 16,3; CI95\%: 51,4-76,4); IIEF$5(19,6 \pm 4,3$; C195\%: 16,2-22,9)], the difference was not statistically significant ( $\mathrm{p}>0.05)$.

Patients who reported an adequate rigidity during intercourse scored significantly higher at the EDITS $(76,8 \pm$ 15,8; CI95\%: 72,5-81,2) and IIEF-5 (22,2 $\pm 4,7$; C195\%: 20,9-23,5) questionnaires than patients with moderate rigidity [EDITS (54,7 $\pm 23,4$; CI95\%: 38,9-70,5); IIEF-5 $(17,7 \pm 7,0 ;$ IC95\%: 12,9-22,5)]. The difference reached statistical significance.

Also patients who reported an excellent/good orgasm scored higher at the EDITS (76,5 $\pm 15,7$; CI95\%: 72,2$80,7)$ and IIEF-5 (22,5 $\pm 3,6$; CI95\%: $21,5-23,5)$ questionnaires than patients who had a moderate/poor orgasm [EDITS (54,5 \pm 25,6; CI95\%: 36,2-72,8); IIEF-5 $(15,8 \pm 9,3$; CI95\%: 9,1-22,5)] and the difference reached statistical significance

The median length of the cylinders in patients who reported an improvement in the quality of sexual life was superior $(19 \pm 1,9$; CI $95 \% 18,5-19,5)$ than the one of

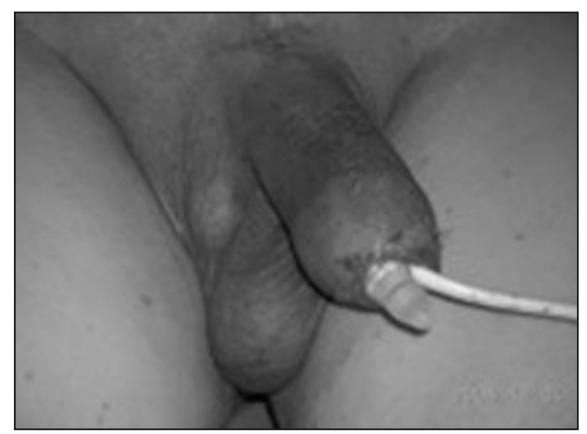

Figure 1.

Erosion of one cylinder through the urethra.

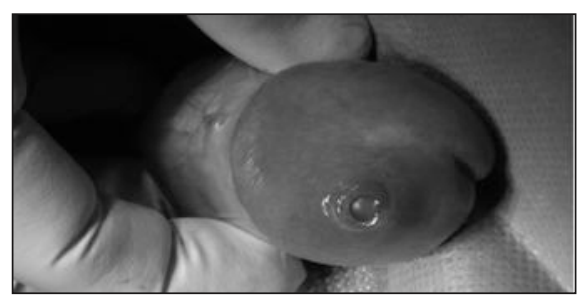

Figure 2.

Erosion through the glans penis. 
patients who did not report an improvement in sexual life $(17,3 \pm 1,9$; CI $95 \% 15,5-19,0)$. This difference was statistically significant $(p=0,0284)$.

Also the cylinders were statistically longer $(19 \pm 1,9$; IC $95 \% 18,5-19,5)$ in patients who would advise a friend to undergo surgery than in patients who would not advise to undergo the procedure $(17,2 \pm 1,7$; IC $95 \% 15,8-18,7)$ $(\mathrm{p}=0,0151)$ and in patients who were globally satisfied (19 $\pm 1,9$; CI 95\% 18,5-19,5) than in patients who were dissatisfied $(17 \pm 1,7$; IC 95\% 15,4-18,6) ( $p=0,0087)$.

There is a progressive but not statistically significant increase in the IIEF-5 and EDITS score with increasing length of the cylinders.

When considering the type of prosthesis implanted, the median EDITS and IIEF-5 score of patients with an AMS 700CX MS [EDITS (74,9 $\pm 15,1$; CI 95\% 69,3-80,6); IIEF-5 (21,5 $\pm 5,0$; CI 95\% 19,6-23,4)] was higher than the one of patients who have undergone implantation of a AMS 700CX tactile pump [EDITS (71,5 $\pm 22,0$; CI 95\% 63,9-70,1); IIEF-5 (21,3 \pm 5,7; CI 95\% 19,4-23,3)], but the difference did not reach statistical significance.

EDITS and IIEF-5 scores were lower in patients who presented comorbidities [EDITS (72,4 $\pm 20,0$; CI95\%: 67,177,7); IIEF-5 (21,1 $\pm 5,7$; CI 95\% 19,6-22,7)] than in patients with no comorbidities [EDITS $(78,1 \pm 9,1$; CI 95\%: 70,5-85,8); IIEF-5 (23,4 \pm 0,9; CI 95\%: 22,6-24,1)], but the difference did not reach statistical significance.

Table 2.

Kaplan Meier overall survival estimate (\%).

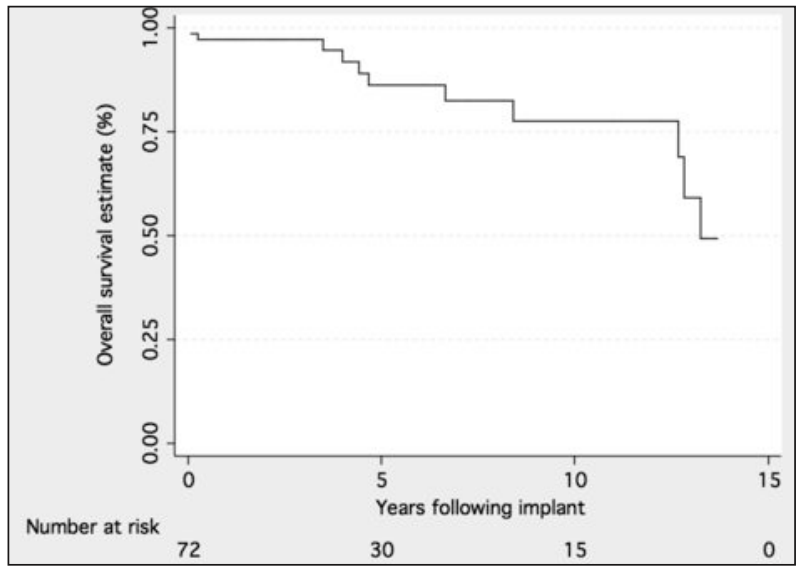

\begin{tabular}{|lcc|}
\hline $\begin{array}{l}\text { Years } \\
\text { following }\end{array}$ & $\begin{array}{c}\text { Overall survival } \\
\text { estimate (\%) }\end{array}$ & [95\% Conf. Int.] \\
\hline 0 & 100 & $\cdot$ \\
\hline 1 & 97,2 & $89,4-99,3$ \\
\hline 2 & 97,2 & $89,4-99,3$ \\
\hline 3 & 97,2 & $89,4-99,3$ \\
\hline 4 & 91,9 & $79,0-97,0$ \\
\hline 5 & 86,4 & $71,3-93,8$ \\
\hline 6 & 86,4 & $71,3-93,8$ \\
\hline 7 & 82,5 & $65,3-91,6$ \\
\hline 8 & 82,5 & $65,3-91,6$ \\
\hline 9 & 77,6 & $58,0-88,8$ \\
\hline 10 & 77,6 & $58,0-88,8$ \\
\hline
\end{tabular}

Table 3.

Kaplan Meier overall survival estimate (\%) according to the type of implant.

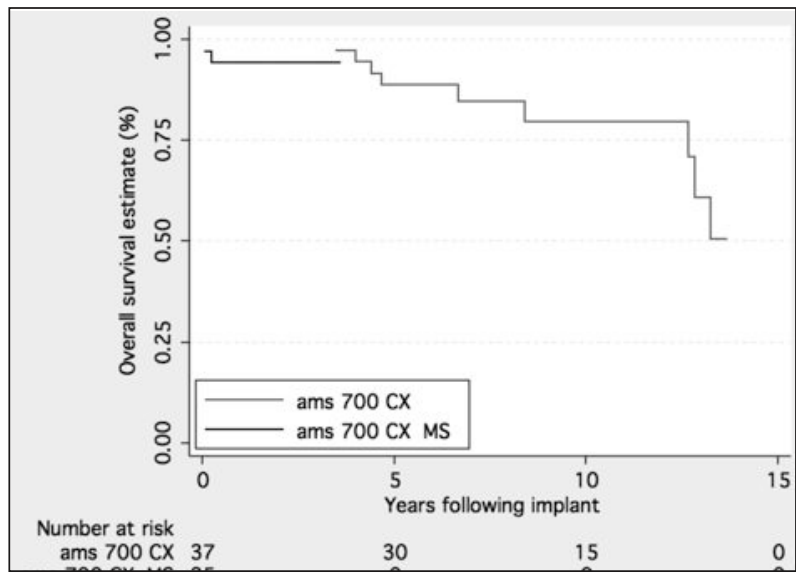

\begin{tabular}{|lccc|}
\hline $\begin{array}{l}\text { Type } \\
\text { of implant }\end{array}$ & $\begin{array}{c}\text { Years } \\
\text { following }\end{array}$ & $\begin{array}{c}\text { Overall survival } \\
\text { estimate (\%) }\end{array}$ & $\begin{array}{c}{[95 \%} \\
\text { Conf. Int.] }\end{array}$ \\
\hline AMS 700 CX & 1 & 100 & - \\
Tactile pump & 3 & 100 & - \\
& 5 & 88,8 & $72,8-95,6$ \\
\hline AMS 700 CX & 1 & 79,7 & $59,2-90,7$ \\
Momentary & 3 & 94,3 & $79,0-98,5$ \\
Squeeze pump & 5 & 94,3 & $79,0-98,5$ \\
& 10 & - & - \\
\hline
\end{tabular}

Overall, patients who have experienced complications scored lower both at the EDITS and IIEF- 5 questionnaires [EDITS $(54,9 \pm 30,1$; CI 95\%: 34,7-75,2); IIEF-5 $(14,4 \pm 10,1$; IC 95\%: 8,6-22,2)] than patients who had no complications [EDITS (75,3 $\pm 16,9$; IC $95 \%$ : 70,8$79,7)$; IIEF-5 (22,3 $\pm 3,9$; IC 95\%: 21,2-23,3)]. The difference reached statistical significance.

Overall 10 years survival estimate according to the Kaplan Meier method of AMS 700 CX touch pump and AMS 700 CX momentary squeeze pump are respectively $77,6 \%$ (IC 95\%: $58,0-88,8$ ) and 82,5\% (IC 95\%: 63,092,2 ), as reported in table 2 and 3 .

\section{Discussion}

Penile prosthesis implantation represents the only solution for patients with refractory erectile dysfunction. Overall, mechanical reliability and overall patients' satisfaction of 3 pieces inflatable penile prosthesis has progressively increased since the first description of a hydraulic device by Scott et al. more than 30 years ago (2).

In particular, 5 years survival can be as high as $92.1 \%$ with patients' satisfaction rates of $85.6 \%$ and a prevalence of mechanical failure of $9.1 \%$ (14- 16).

The main limitation of all these studies is that patients' satisfaction was assessed subjectively by the surgeon and not with a validated questionnaire. Mulhall et al. in 2003 has been the first to use validated questionnaires such as IIEF- 
5 and EDITS to assess patients' satisfaction 6 months postoperatively (10). The present series using validated questionnaires confirms a statistically significant correlation between mechanical complications, degree of rigidity and quality of the orgasm with patient's satisfaction. Interestingly, the quality of sensation did not affect IIEF-5 and EDITS scores in a statistically significant way.

Overall $87.7 \%$ of the patients in the present series were satisfied with the cosmetic and functional result of surgery, and these results are similar to the one previously reported in the literature $(17,18)$. Also median prosthesis survival rate in the present series was $97.2 \%$ at 1 year, $91.9 \%$ at 4 years and $77.6 \%$ at 10 years, substantially similar to the data reported by Dhar et al. (19).

The strength of our results has been to have used a validated questionnaires to assess the functional results, compared with other previously similar experiences.

Some limits of our study must be underlined: First, this is a retrospective analysis and not a prospective and randomized study. Second, the follow-up was not so longer (68.7 months) to better evaluate the satisfaction of patients in a long time from surgery, however it is similar to previous experience in this field.

\section{Conclusions}

Penile prosthesis implantation yields excellent results in terms of cosmetic and functional outcome and therefore has a significant impact on patients' satisfaction, sex life and overall quality of life. Overall, long term reliability has been significantly improved and complication rates are low in the hands of experienced surgeons.

\section{REFERENCES}

1. Montague DK. Penile prosthesis implantation in the era of medical treatment for erectile dysfunction. Urol Clin North Am. 2011; 38:217-25

2. Scott FB, Bradley WE, Timm GW. Management of erectile impotence: use of implantable inflatable prosthesis. Urology. 1973; 2:80.

3. Nickas ME, Kessler R, Kabalin JM. Long term experience with controlled expansion cylinders in the AMS 700 CX inflatable penile prosthesis and comparison with earlier version of the Scott inflatable penile prosthesis. Urology. 1994; 44:400.

4. Milbank AJ Montague DK, Angermeier KW, et al. Mechanical failure of the American Medical System Ultrex inflatable penile prosthesis: before and after 1993 structural modification. J Urol. 2002; 167:2502-6.

5. Daitch JA, Angermeier KW, Lakin MM, et al. Long Term Mechanical Reliability of AMS 700 series inflatable penile prostheses: comparison of CX/CXm and ultrex cylinders. J Urol. 1997; 158:1400.

6. Wilson SK, Cleves MA, Delk JR $2^{\text {nd }}$. Comparison of mechanical reliability of original and enhanced Mentor Alpha I penile prosthesis. J Urol. 1999; 162:715-8.

7. Delk J, Knoll LD, Mc Murray J, et al. Early experience with the American medical system new tactile pump: results of a multicentre study. J Sex Med. 2005:266-71.

8. Knoll LD, Henry G, Culkin D, et al. Physician and patient satisfaction with the new ams700 momentary sqeeze inflatable penile prosthesis. J Sex Med. 2009; 6:1773-8.
9. Carson CC Efficacy of antibiotic impregnation of inflatable penile prosthesis in decreasing infection in original implants. J Urol. 2004; 171:1611-1614

10. Carson CI. Initial success with the AMS 700 series inflatable penile prosthesis with inhibizione antibiotic surface treatment: a retrospective review of revision cases incidence and comparative results versus non-treated devices. J Urol. 2004; 171:236.

11. Mc Laren RH, Barret DM. Patient and partner satisfaction with the AMS 700 penile prosthesis. J Urol. 1992; 147:62.

12. Mulhall JP, Ahmed A, Branch J, Parker M. Serial assessment of efficacy and satisfaction profiles following penile prosthesis surgery. J Urol. 2003; 169:1429-1433.

13. Althof SE, Corty EW, Levine SB, et al. EDITS: development of questionnaires for evaluating satisfaction with treatments for erectile dysfunction. Urology. 1999; 53:793-9.

14. Carson CC Penile prosthesis implantation in the treatment of Peyronie desease" Int J Imp Res. 1998; 10:125.

15. Choi Deuk Y, Jin Choi Y, Hwan Kim J, Ki Choi H. Mechanical reability of the AMS $700 \mathrm{cmx}$ inflatable penile prosthesis for the treatment of male erectile dysfunction. J Urol. 2001; 165:822-4.

16. Carson CC, Mulcahy JJ, Govier FE. Efficacy, safety and patient satisfaction outcome of the ams $700 \mathrm{cx}$ inflatable penile prosthesis: result of a long term multicenter study. Ams $700 \mathrm{cx}$ study group. J Urol. 2000; 164:376-80.

17. Bhojwani AG, Jain S, Kockelbergh RC, Terry TR. Sexual satisfaction after penile prosthesis insertion for the treatment of erectile dysfunction. Sex Dysfunction. 1998; I:133-136.

18. Goldstein I, Jain L, Kockelbergh RC, Terry TR. Safety and efficacy outcome of mentor alphal inflatable penile prosthesis implantation for impotence treatment. J Urol 1997; 157:833-9.

19. Dhar NB, Angermeier KW, Montague DK. Long-term mechanical reliability of AMS 700CX Тм/CXM Inflatable penile prosthesis. J Urol. 2006; 176:2599-2601.

\section{Correspondence}

Antonio Vitarelli, MD - antoniovitarelli@hotmail.com Lucia Divenuto,MD - ldivenuto@urologia.uniba.it Vincenzo Pagliarulo, MD - vpagliarulo@urologia.uniba.it ArcangeloPagliarulo,MD - apagliarulo@urologia.uniba.it Urologia II Universitaria, Department of Emergency and Transplant, Section of Urology and Andrology, University Hospital, Azienda Ospedaliera Policlinico, Bari, Italy

Francesca Fortunato, MD - f.fortunato@unifg.it Department of Medical Sciences and Occupational Medicine, Section of Hygiene, University of Foggia, Foggia, Italy

Antonio Falco, MD - a.falco@unifg.it

Epidemiologic Observatory of Puglia, Foggia Italy

Stefano Salciccia, MD (Corresponding Author) -stefi_sal77@tiscali.it Gabriele Antonini, MD - gabrieleantoninimd@gmail.com Vincenzo Gentile, MD - vincenzo.gentile@uniromal.it Alessandro Sciarra, MD - sciarrajß@hotmail.com Maria Rosaria Di Placido,MD - m.diplacido@uniromal.it Department of Urology, University "La Sapienza", Viale del Policlinico 155 - 00161 Roma, Italy

Salvatore Sansalone, MD - salvatore.sansalone@yahoo.it Department of Urology, Tor Vergata, University, Rome, Italy

Giulio Garaffa, MD - giuliogaraffa@gmail.com

St. Peter's Andrology and the Urology Centre, Broomfield Hospital Chelmsford (UK) 